\title{
EXPERIMENTAL STUDY OF THE EXTRACTION OF CHROMIUM (III) FROM NITRATE MEDIUM BY LAURIC ACID
}

\author{
Amel Guerdouh ${ }^{1,2}$ *, Djamel Barkat ${ }^{2}$ \\ ${ }^{1}$ Faculty of Applied Sciences, Kasdi Merbah University- Ouargla, Algeria \\ ${ }^{2}$ Laboratory of Chemical Molecular and Environment, Department of \\ Industrial Chemistry, Faculty of Sciences and Technology, Biskra University, \\ Biskra, Algeria
}

Received 25.09.2018.

Accepted 16.10.2018.

\begin{abstract}
The solvent extraction of chromium (III) with lauric acid (HL) at $25^{\circ} \mathrm{C}$ is studied as a function of various parameters: $\mathrm{pH}$ of the aqueous phase, the concentration of lauric acid and the nature of the solvent. The solvent effects on the extraction of chromium (III) using polar and nonpolar solvents has been observed. It was shown that extracted species of the $\left[\mathrm{Cr}(\mathrm{OH}) \mathrm{L}_{2} \cdot 2 \mathrm{HL}\right]$ formula are formed in cyclohexane, dichloromethane, chloroform, and toluene. However, in 1-octanol or methyl isobutyl ketone, it was found a complex of the type $\left[\mathrm{Cr}(\mathrm{OH}) \mathrm{L}_{2}\right]$. The extraction constants and extraction yield $(\% E)$ are also calculated for different solvents. It was found that cyclohexane is the preferred solvent for this extraction system. The maximum extraction yield is accomplished using the cyclohexane as a solvent on 1:1 L/L ratio, and $\mathrm{pH}$ value of 4.73 .
\end{abstract}

Keywords: chromium (III); distribution coefficient; extraction; lauric acid; solvent effects.

\section{Introduction}

Solvent extraction is a very successful method for the separation of metals from aqueous solution [1-6]. The extraction of metals using carboxylic acids has been a subject of numerous researches [7-10]. Carboxylic acids were employed as ligands for the separation of various cations, the composition of extracted species and their extraction constants were reported [3,11-13]. However, the literature concerning the extraction of chromium (III) contains little or no information using carboxylic acids. The extraction of chromium(III) from chloride using hexanoic acid dissolved in carbon tetrachloride has

*Corresponding author: Amel Guerdouh, guerdouh.amel@univ-ouargla.dz, amelguerdouh@yahoo.fr 
been reported by Apostoluk et al. [14]. They argued that the dependence on initial chromium (III) concentration indicated the formation of polynuclear chromium (III) complexes. It was found that in the organic phase trinuclear complexes of the $\left[\mathrm{Cr}(\mathrm{OH}) \mathrm{R}_{2}\right] \cdot \mathrm{HR}$ formula are formed.

This work deals with the solvent extraction of chromium (III) by lauric acid dissolved in several solvents such as cyclohexane, dichloromethane, chloroform, toluene, 1-octanol, and MIBK. Moreover, we report an investigation aimed at gaining information about the best solvent for this extraction system in order to improve the parameters of extraction and to increase the extractability of lauric acid. The stoichiometry coefficients of the extracted species, equilibrium constants and extraction yield (\%E) are determined for different solvents.

\section{Experimental}

\section{Reagents and solutions}

Lauric acid ( $>99 \%$, Biochem), chromium nitrate ( $>99 \%$, Biochem) and sodium nitrate (>99\%, Biochem) were used without further purification. Chloroform, toluene, dichloromethane, cyclohexane, 1-octanol and methyl isobutyl ketone (MIBK) $(>99 \%$, obtained from Sigma Aldrich) were employed as the organic solvents. The 1- decanol ( $>99 \%$, obtained from Sigma Aldrich) used as a modifier in the organic phase. The ionic strength of the aqueous medium was assumed to be unity $\left(\left[\mathrm{NaNO}_{3}\right]=1 \mathrm{M}\right)$. Aqueous phase: $\left[\mathrm{Cr}^{3+}\right]=1.92 \times 10^{-3} \mathrm{M} ;\left[\mathrm{NaNO}_{3}\right]=1 \mathrm{M}$. Organic phase: $\left[\mathrm{C}_{12} \mathrm{H}_{24} \mathrm{O}_{2}\right]=0.01,0.02$ and $0.04 \mathrm{M}$.

\section{Extraction Procedure}

An aqueous solution containing $1.92 \times 10^{-3} \mathrm{M}$ metal was equilibrated (phase equilibrium.) with equal volumes $(40 \mathrm{ml})$ of the solvents solutions of the ligand $0.01,0.02$ and $0.04 \mathrm{M}$ by shaking in a mechanical shaker at $\mathrm{T}=20^{\circ} \mathrm{C}$. The $\mathrm{pH}$ of the aqueous phase was adjusted by adding the necessary amount of $0.05 \mathrm{M} \mathrm{NaOH}$. Then, after shaking beakers for several hours, the organic phase was separated from the aqueous phase by sedimentation, the aqueous phase was filtered, and the $\mathrm{pH}$ was measured. Concentrations of chromium in the aqueous phase were determined by Philips UV-VIS SP6-36. The metal ion concentrations in the organic phase were calculated from the difference between the metal ion concentrations in the aqueous phase before and after extraction.

\section{Results and Discussion}

General treatment of extraction equilibrium of chromium (III) with lauric acid

Carboxylic acids are present as dimeric species in nonpolar solvents such as toluene, hexane or benzene $[11,13]$ and as monomeric species in polar solvents such as 1-octanol,and 4-methyl-2-pentanone.[15, 16]. The extraction equilibrium in nonpolar solvents may be represented by the equation:

$$
M(O H)_{(3-n), a q}^{n+}+\frac{(n+m)}{2}(H L)_{2, \text { org }} \stackrel{K_{e x l}}{\longleftarrow}\left(M(O H)_{3-n} L_{n} \cdot m H L\right)_{o r g}+n H^{+}
$$

where the equilibrium constant $\mathrm{K}_{\mathrm{ex} 1}$ is defined by Equation (2). 
$K_{e x l}=\frac{\left[\left(M(O H)_{3-n} L_{n}\right) \cdot m H L\right]_{o r g}\left[H^{+}\right]^{n}}{\left[M(O H)_{3-n}^{n+}\right]_{a q}\left[(H L)_{2}\right]_{o r g}^{(n+m) / 2}}$

The distribution ratio, $\mathrm{D}$, is given by Equation (3).

$\log D=\frac{n+m}{2} \log \left[(H L)_{2}\right]_{\text {org }}+n p H+\log K_{\text {exl }}$

However, in polar solvents, equations (1), (2) and (3) become:

$$
\begin{aligned}
& M(\mathrm{OH})_{3-n, a q}^{n+}+(n+m)(H L)_{\text {org }} \stackrel{K_{\text {ex }}}{\rightleftarrows}\left(M(\mathrm{OH})_{3-n} L_{n}\right) \cdot m H L_{\text {org }}+n H^{+} \\
& K_{\text {exz }}=\frac{\left[\left(M(\mathrm{OH})_{3-n} L_{n} \cdot m H L\right)\right]_{\text {org }}\left[H^{+}\right]^{n}}{\left[M(\mathrm{OH})_{3-n}^{n+}\right]_{a q}[(H L)]_{\text {org }}(n+m)} \\
& \log D=(n+m) \log [(H L)]_{\text {org }}+n p H+\log K_{\text {ex2 }}
\end{aligned}
$$

where the species in the aqueous and organic phases are designated by the subscripts aq. and org. respectively. Other parameters are defined as: complex,

$\mathrm{M}=\mathrm{Cr}^{3+}, \mathrm{n}=$ cationic charge, $\mathrm{m}=$ number of monomeric acids contained in the

$(\mathrm{HL})_{2} ;(\mathrm{HL})=$ ligand in dimeric and monomeric form respectively.

The stoichiometry of the extracted species was determined by using the method of slope analysis. Therefore, the extraction yield (\%E) of chromium (III) can be calculated by:

$$
\mathrm{E}=\frac{\mathrm{D}}{\mathrm{D}+1} \times 100
$$

\section{Analysis of the extraction of chromium (III) with lauric acid in different solvents}

Effect of the equilibrium $p H$

According to equations (3) and (6), plots, $\log \mathrm{D}$ versus $\mathrm{pH}$ are determined at a constant concentration of lauric acid dissolved in cyclohexane, dichloromethane, chloroform, toluene, 1-octanol, and MIBK, as shown in Fig. 1. 


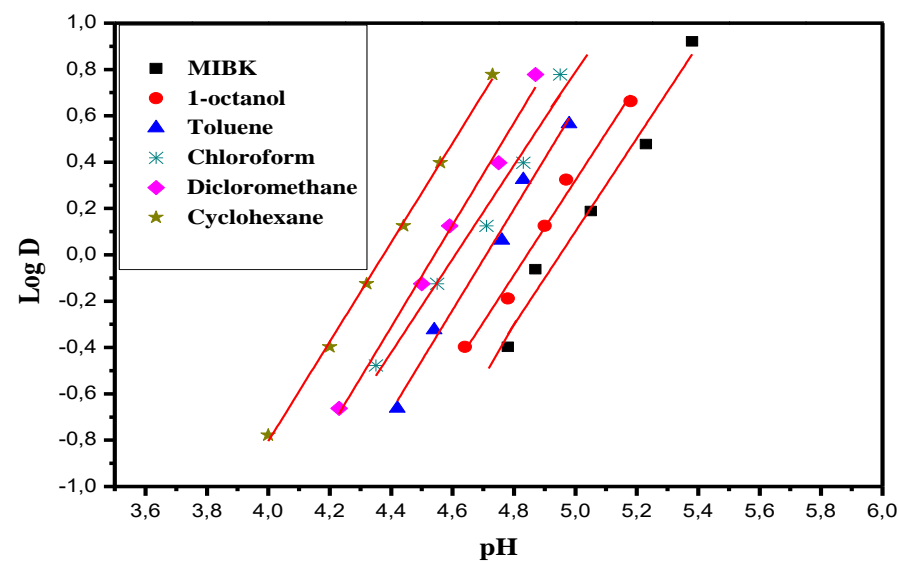

Fig. 1. Logarithmic value of the distribution coefficient as a linear function of the $\mathrm{pH}$ value gained from the experiment extraction of chromium (III) with lauric acid dissolved in different solvents. $[\mathrm{HL}]=0.04 \mathrm{M} ;\left[\mathrm{Cr}^{3+}\right]=1.92 \times 10^{-3} \mathrm{M}$.

Linear relations are observed with the slope of two $(n=2)$. This means that two protons are liberated during the extraction process. Also, the results obtained show that the extraction process increased with increasing the $\mathrm{pH}$ of the aqueous phase.

\section{Effect of lauric acid concentration}

Fig. 2 shows the effect of lauric acid concentration on the chromium extraction in nonpolar solvents such as cyclohexane, dichloromethane, chloroform, and toluene. Concentration of dimer was calculated as: $\left[(\mathrm{HL})_{2}\right]=[\mathrm{HL}] / 2$.

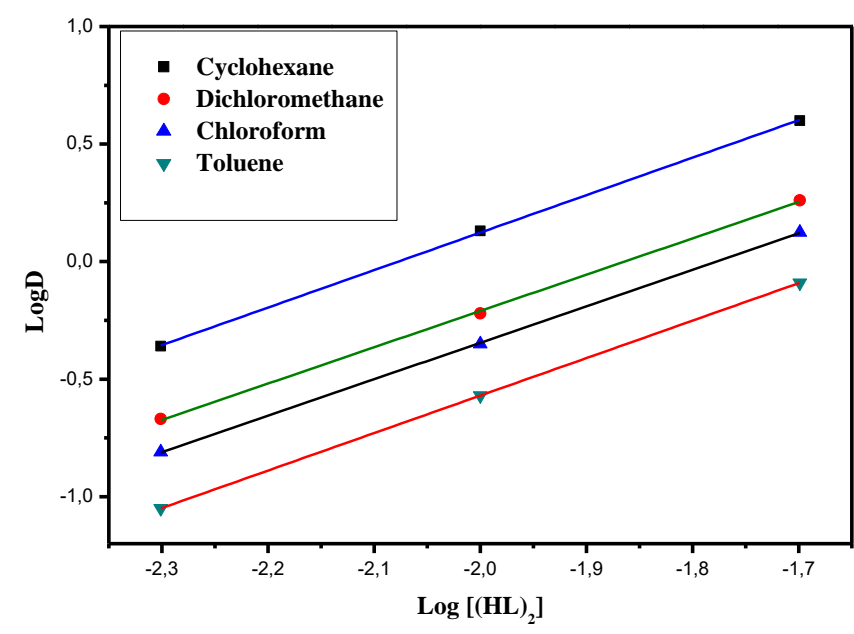

Fig. 2. Determination of the number of lauric acid molecules involved in the extracted species in nonpolar solvents. 
The data obtained from Fig 2 indicate that relationships $\log \mathrm{D}$ versus $\log \left[(\mathrm{HL})_{2}\right]_{\text {org }}$ were linear with a slope about 2 , that is, $(2+\mathrm{m}) / 2=2$ or $\mathrm{m}=2$. Consequently, the composition of the extracted species in nonpolar solvents is $\left[\mathrm{Cr}(\mathrm{OH}) \mathrm{L}_{2}(\mathrm{HL})_{2}\right]$. The same complex was obtained by K. Kimura [17] on the solvent extraction of chromium (III) from sulfate medium with D2EHPA acid dissolved in toluene. Therefore, equations (1) and (3) could be rewritten as:

$$
\begin{aligned}
& \mathrm{Cr}(\mathrm{OH})_{a q}^{+2}+2(\mathrm{HL})_{2, \text { org }} \stackrel{K_{\text {exl }}}{\leftleftarrows}\left(\mathrm{Cr}(\mathrm{OH}) L_{2} \cdot 2 \mathrm{HL}\right)_{\text {org }}+2 \mathrm{H}^{+} \\
& \log \mathrm{D}=\log \mathrm{K}_{\mathrm{ex} 1}+2 \log \left[(\mathrm{HL})_{2}\right]_{\mathrm{org}}+2 \mathrm{pH}
\end{aligned}
$$

However, in polar solvents as 1-octanol and MIBK, Plots of log D versus $\log [\mathrm{HL}]_{\text {org }}$ at constant $\mathrm{pH}$ were linear with slopes closure to 2 (Fig 3 ), that is, $(2+\mathrm{m}) \sim 2$ or $\mathrm{m} \sim 0$. This means that the extracted species in the organic phase is $\mathrm{Cr}(\mathrm{OH}) \mathrm{L}_{2}$. These results are similar to those published by F. Islam et al. [18]. Equations (4) and (6) could be rewritten as:

$$
\mathrm{Cr}(\mathrm{OH})_{a q}^{+2}+2(\mathrm{HL})_{\text {org }} \stackrel{K_{\text {ex2 }}}{\rightleftarrows} \mathrm{Cr}(\mathrm{OH}) L_{2}+2 \mathrm{H}^{+}
$$

$$
\log D=\log K_{\text {ex }}+2 \log [(H L)]_{\text {org }}+2 \mathrm{H}^{+}
$$

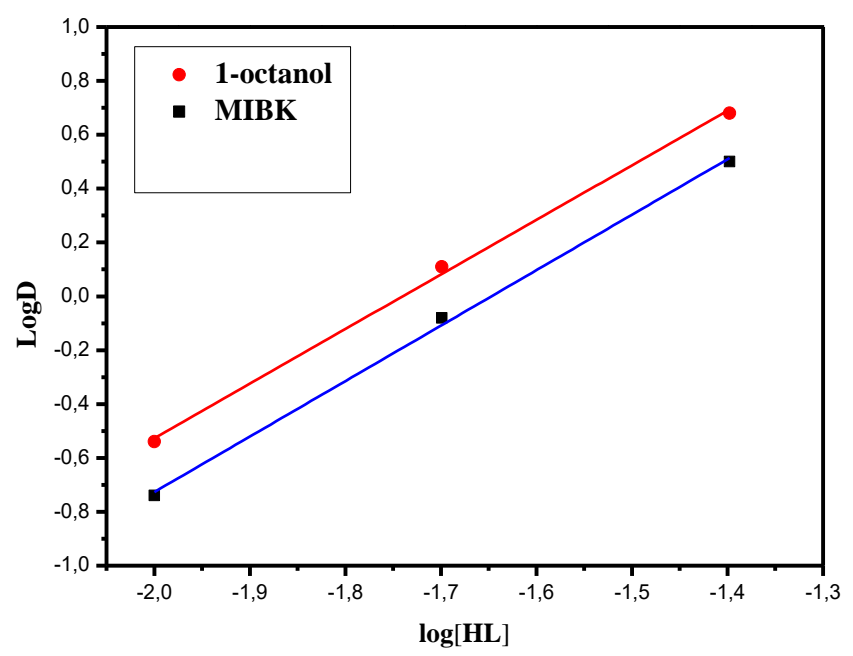

Fig. 3. Determination of the number of lauric acid molecules involved in the extracted species in polar solvents. 
The distribution coefficient (D) and extraction yield (\%E) were calculated to establish the extracting capability of the ligand (lauric acid) dissolved in various solvents (Tables 1).

Table 1. Effect of lauric acid concentration $(H L)$ diluted in different solvents on the extraction percentage (\%E) of chromium (III) at $\mathrm{pH}=4.6$.

\begin{tabular}{|c|c|c|c|c|c|c|c|c|c|c|c|}
\hline Solvent & Cyclo & hexane & Dichl & rometha & e Chloroform & Tolt & uene & $1-\mathrm{OC}$ & tanol & MIB & \\
\hline $\begin{array}{l}{[\mathrm{HL}]} \\
(\mathrm{mol} / \mathrm{l})\end{array}$ & $\mathrm{D}$ & $\mathrm{c} / \mathrm{E}$ & $\mathrm{D}$ & $\mathrm{c} / \mathrm{E}$ & $\mathrm{D} \quad \mathrm{c} \mathrm{E}$ & $\mathrm{D}$ & $\mathrm{c} / \mathrm{E}$ & $\mathrm{D}$ & $\mathrm{c} / \mathrm{E}$ & $\mathrm{D}$ & $\mathrm{c} / \mathrm{E}$ \\
\hline 0.01 & 0.43 & 0.0 & 0.2 & & 0.15 & 0.09 & 98.25 & 0.0 & .96 & 0.01 & 1.01 \\
\hline 0.02 & 1.35 & 57.44 & 0.60 & 37.50 & 0.4531 .03 & 0.2 & 21.26 & 0.0 & 7.40 & 0.05 & 4.76 \\
\hline 0.04 & 3.91 & 80.01 & 1.82 & 64.54 & $1.32 \quad 56.90$ & 0.81 & 44.75 & 0.31 & 23.6 & 50.21 & 17.35 \\
\hline
\end{tabular}

The distribution coefficient (D) and extraction percentage $(\% \mathrm{E})$ increased with increasing of lauric acid concentration. It can be found that the recovery of chromium (III) reached $80.01 \%, 64.54 \% 56.90 \%, 44.75 \%, 23.66 \%$ and $17.35 \%$ for cyclohexane, dichloromethane, chloroform, toluene 1 -octanol and MIBK respectively at $[\mathrm{HL}]=0.04 \mathrm{M}$.

Table 2 gives the stoichiometries of the extracted chromium species with lauric acid in different solvents and their extraction constants.

Table 2. Extracted species and extraction constants of solvent extraction of chromium (III) with lauric acid.

\begin{tabular}{lll}
\hline Solvent & $\operatorname{logK}_{\mathrm{ex}}$ & Extracted species \\
\hline Cyclohexane & -5.07 & {$\left[\mathrm{Cr}(\mathrm{OH}) \mathrm{L}_{2} \cdot 2(\mathrm{HL}) \cdot \mathrm{H}_{2} \mathrm{O}\right]$} \\
Dichloromethane & -5.42 & {$\left[\mathrm{Cr}(\mathrm{OH}) \mathrm{L}_{2} \cdot 2(\mathrm{HL}) \cdot \mathrm{H}_{2} \mathrm{O}\right]$} \\
Chloroform & -5.54 & {$\left[\mathrm{Cr}(\mathrm{OH}) \mathrm{L}_{2} \cdot 2(\mathrm{HL}) \cdot \mathrm{H}_{2} \mathrm{O}\right]$} \\
Toluene & -5.76 & {$\left[\mathrm{Cr}(\mathrm{OH}) \mathrm{L}_{2} \cdot 2(\mathrm{HL}) \cdot \mathrm{H}_{2} \mathrm{O}\right]$} \\
1-octanol & -6.91 & {$\left[\mathrm{Cr}(\mathrm{OH}) \mathrm{L}_{2} \cdot \mathrm{H}_{2} \mathrm{O}\right]$} \\
MIBK & -7.08 & {$\left[\mathrm{Cr}(\mathrm{OH}) \mathrm{L}_{2} \cdot \mathrm{H}_{2} \mathrm{O}\right]$} \\
\hline
\end{tabular}

Effect of solvents on the chromium (III) extraction

In order to examine the impact of the solvent on the extraction efficiency, several organic solvents such as cyclohexane, dichloromethane, chloroform, toluene, 1-octanol, and MIBK were used at a constant $\mathrm{pH}=4.7$. The results obtained from Fig4 and table 2 confirmed that the nonpolar solvents showed better performance in chromium (III) extraction than polar solvents. 


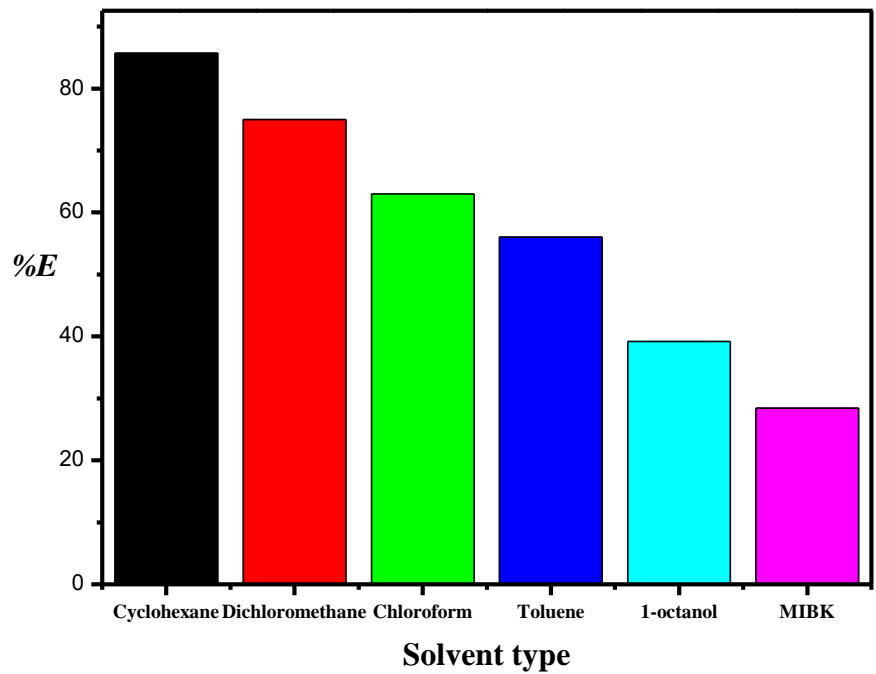

Fig. 4. Effect of solvents on the extraction efficiency of chromium (III) with lauric acid; $[\mathrm{HL}]=0.04 \mathrm{M} ;\left[\mathrm{Cr}^{3+}\right]=1.92 \times 10^{-3} \mathrm{M}$.

This result is similar to that obtained in the literature[19]. Also, it is clear that the cyclohexane was as the favored solvent for this extraction system, may be assigned to the absence of interactions between the extractant and this solvent. Moreover, the extraction of chromium (III) in dichloromethane is better than in chloroform and toluene; these results may be explained by the fact that dielectric constant of the solvent plays a significant role in expected extraction yield value. Dichloromethane has high dielectric constant, therefore, it is preferable solvent for extracting metal ions. In addition, the better solvation of the complexes by dichloromethane may be a valuable reason for better extraction [20, 21]. However, in polar solvents, 1-octanol and MIBK, it was found that the distribution coefficient decreased as the polarity of solvents increased. This can be explained by the fact that the polar solvents are capable of forming hydrogen bonds with electron donor atoms of lauric acid that lead to a reduction in the active concentration of the lauric acid, consequently, poorer extraction of chromium results. In methyl isobutyl ketone (MIBK), the extraction proceeds quickly, and a few amounts of metal was extracted than that in 1-octanol, would probably expound by the stronger chemical interaction between MIBK and lauric acid, in addition to the solubility of this solvent in the aqueous phase.

Spectroscopic studies of extracted species

The visible spectra of the loaded organic phase were performed in cyclohexane, toluene, dichloromethane, chloroform, MIBK and 1-octanol (Fig 5). 


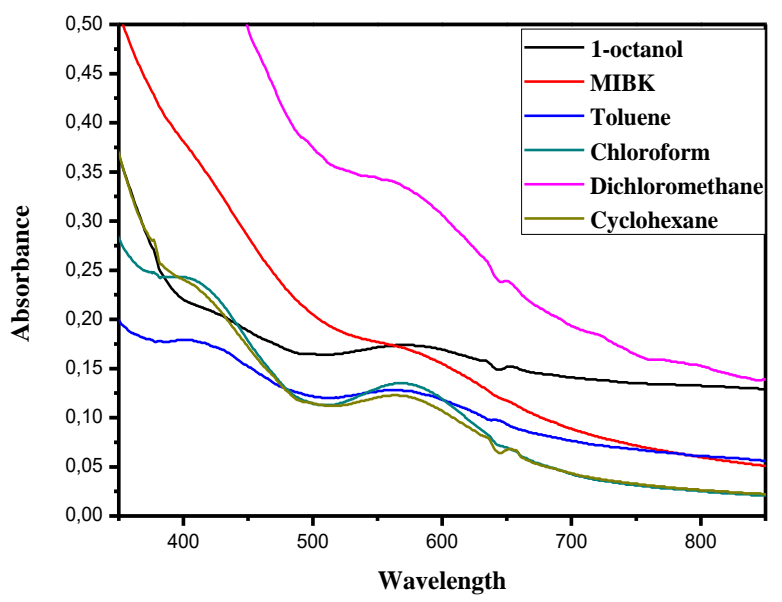

Fig. 5. Visible spectra of chromium complexes in different solvents.

The visible spectra of the loaded organic phase show an absorbance in the 550-575 $\mathrm{nm}$ region, which indicated to octahedral geometry coordination of the extracted complex [22]. This means that two molecules of lauric acid coordinating with the central chromium ion, water, and hydroxyl molecules would complete the coordination sphere so that the chromium ion could obtain a stable structure. On the basis of this explanation, the possible structure of the extracted complexes can be represented as shown in Fig 6 and Fig7.

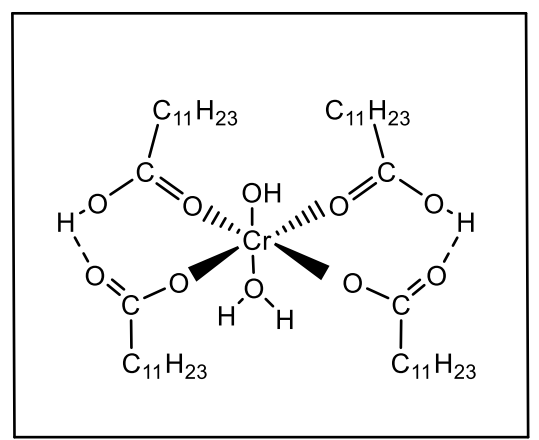

Fig. 6. The structure of the complex $\mathrm{Cr}(\mathrm{OH}) \mathrm{L}_{2} \cdot 2(\mathrm{HL}) \mathrm{H}_{2} \mathrm{O}$.

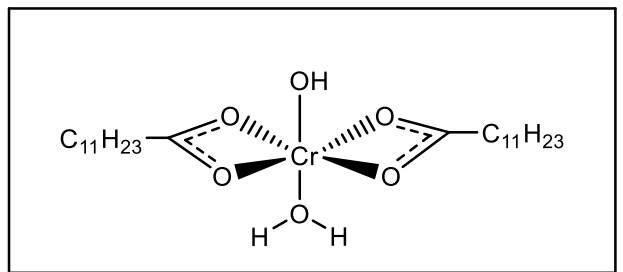

Fig. 7. The structure of the complex $\mathrm{Cr}(\mathrm{OH}) \mathrm{L}_{2} \cdot \mathrm{H}_{2} \mathrm{O}$. 


\section{Conclusion}

The experimental data has established the possibility of using lauric acid to recover chromium (III) from aqueous solutions. An increase in the $\mathrm{pH}$ and lauric acid concentration has a positive effect on the extraction process. The extraction of chromium (III) with lauric acid may be represented by the following equations:

$$
\begin{array}{lll}
\mathrm{Cr}(\mathrm{OH})_{a q}^{+2}+2(\mathrm{HL})_{2, \text { org }} \stackrel{\mathrm{K}_{\text {exl }}}{\longleftarrow}\left[\left(\mathrm{Cr}(\mathrm{OH}) L_{2} \cdot 2 \mathrm{HL}\right)\right]+2 H^{+} & \text {for non polar solvents } \\
\mathrm{Cr}(\mathrm{OH})_{a q}^{+2}+2(\mathrm{HL})_{\text {org }} \stackrel{K_{\text {ex } 2}}{\longleftarrow}\left[\left(\mathrm{Cr}(\mathrm{OH}) \mathrm{L}_{2}\right)\right]+2 \mathrm{H}^{+} & \text {for non polar solvents }
\end{array}
$$

The nonpolar solvents are better performance than the polar solvents and the extraction capacity of lauric acid in different solvents decreases in the order: cyclohexane $>$ dichloromethane $>$ chloroform $\geq$ toluene $>1$-octanol $>$ MIBK .

\section{References}

[1] A. Guerdouh, D. Barkat: J Disp Sci Tech, 38 (2017) 930-934.

[2] A. Guerdouh, D. Barkat: J Fundam Appl Sci, 8 (2016) 387-400.

[3] A. Guerdouh, D. Barkat: J Thermody Catal, 6 (2) (2015) 1-7, 148

[4] A. Aidi , D.Barkat: J Coord Chem, 63 (2010) 4136-4144.

[5] F. Ghebghoub , D.Barkat: J Coord Chem, 62(2009) 1449-1456.

[6] D. Barkat , M. Kameche: Phys Chem Liq, 45 (2007) 289 - 293.

[7] F. Adjel , D. Barkat: J Coord Chem, 64 (2011) 574-582.

[8] Y.Baba, K. Inoue: Hydrometallurgy, 21(1988) 203-212.

[9] JS.Preston: Hydrometallurgy, 14 (1985) 171- 188.

[10] F M. Doyle, D. Pouillon: Hydrometallurgy, 19 (1988) 289-308.

[11] M P .Elizalde, J M astresana, M C Alonso: Polyhedron, 4 (1985) 2097-2101.

[12] M P Elizalde, J M Castresana, A I Elorriaga: Polyhedron, 6 (1987) 2155-2160.

[13] K. Oukebdane , M.A. Didi, A.Azzouz , D.Villemin: Sc.Study \& Res, (1-2) (2004) 59-64.

[14] W. Apostoluk, A.Bartecki: Hydrometallurgy, 15 (1985) 191-202.

[15] [H. Yamada, S. Suzuki , M. Tanaka, J Inorg Nucl Chem, 43 (1981) 1873-1879.

[16] G K Schweitzer, D K. Morris: Anal Chim Acta, 45 (1969) 65-70.

[17] K. Kimura, Bull Chem Soc Jpn, 33 (1960) 1038-1046.

[18] F B .Islam, J. Inorg: Nucl Chem, 41 (1979) 229-233.

[19] H.Yamada, S.Imai , E.Takeuchi: Bull Chem Soc Jpn, 56 (1983) 1401-1406.

[20] W. Al Zoubi, F.Kandil, M K.Chebani: Org Chem Current Res, 2012, 1: 104.

[21] B O. Strasser, A I. Popo: J Am Chem Soc, 107 (1985) 7921-7924.

[22] M D.Lanagan, D C. Ibana: Minerals Engineering, 16 (2003) 237-245.

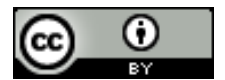

Creative Commons License

This work is licensed under a Creative Commons Attribution 4.0 International License. 